\section{Conflict of interest}

The authors declare no conflict of interest.

\section{References}

1 Wu W, Dawson DG, Sugar A, Elner SG, Meyer KA, McKey JB et al. Cataract surgery in patients with nanophthalmos: results and complications. J Cataract Refract Surg 2004; 30(3): 584-590.

2 Yuzbasioglu E, Artunay O, Agachan A, Bilen H. Phacoemulsification in patients with nanophthalmos. Can J Ophthalmol 2009; 44(5): 534-539.

3 Yalvac IS, Satana B, Ozkan G, Eksioglu U, Duman S. Management of glaucoma in patients with nanophthalmos. Eye 2008; 22(6): 838-843

4 Faulborn J, Kolli H. Sclerotomy in uveal effusion syndrome. Retina 1999; 19(6): 504-507.

5 Rufer F, Varde MA, Roider J. Intravitreal triamcinolone and bevacizumab injections for alternative treatment of nanophthalmic uveal effusion syndrome. Klin Monatsbl Augenheilkd 2008; 225(6): 594-596.

E Gosse, A Gittos and J Lochhead

Department of Ophthalmology, St Mary's Hospital, Isle of Wight, UK

E-mail: emilygosse@doctors.org.uk

Eye (2011) 25, 528-529; doi:10.1038/eye.2010.219; published online 21 January 2011

\section{Sir, \\ A possible genetic answer to a recently reported novel phenotype}

We read with interest the recent article of Shen et al, ${ }^{1}$ who report a unique Chinese pedigree with the features of ectopia lentis and varicose great saphenous vein. Marfan's syndrome (MFS), clinically diagnosed by characteristic multiple-system abnormalities, lies at one end of a phenotypic spectrum. At the other end of that spectrum are members of the general population who have one feature common to those with MFS. ${ }^{2}$ Of those patients who fulfil the modified Ghent criteria for full MFS, up to $97 \%$ are found to have FBN1 mutations. ${ }^{3}$ However, the patients presented by Shen et al are atypical. An alternative approach would be to try to postulate an all-encompassing molecular diagnosis that best fits the clinical signs. Venous varicosity is usually secondary to valvular incompetence, a condition that has been strongly associated with heterozygous mutations in the FOXC2 gene on chromosome $16 .{ }^{4}$ Similarly, a range of anterior segment phenotypes have been described, with mutations in FOXC2 inherited in a dominant manner. ${ }^{5}$ When aiming for a genetic diagnosis in this family, we would therefore advocate including FOXC2 in the screening set of genes. If a FOXC2 mutation were found in this family, this would represent an interesting extension to the associated phenotype.

\section{Conflict of interest}

The authors declare no conflict of interest.

\section{References}

1 Shen W, Fu Q, Sui R, Wu J, Liu L. Unique phenotype in a Chinese family pedigree: ectopia lentis with varicose great saphenous vein. Eye 2010; 24(10): 1614-1617.

2 Pyeritz RE. The Marfan syndrome. Annu Rev Med 2000; 51: 481-510.

3 Loeys BL, Dietz HC, Braverman AC, Callewaert BL, De Backer J, Devereux RB et al. The revised Ghent nosology for the Marfan syndrome. J Med Genet 2010; 47(7): 476-485.

4 Mellor RH, Brice G, Stanton AW, French J, Smith A, Jeffery S et al. Mutations in FOXC2 are strongly associated with primary valve failure in veins of the lower limb. Circulation 2007; 115(14): 1912-1920.

5 Smith RS, Zabaleta A, Kume T, Savinova OV, Kidson SH, Martin JE et al. Haploinsufficiency of the transcription factors FOXC1 and FOXC2 results in aberrant ocular development. Hum Mol Genet 2000; 9(7): 1021-1032.

K Khan, M Ali and C Inglehearn

Leeds Institute of Molecular Medicine, St James' University Hospital, Leeds, Yorkshire, UK E-mail: medknk@leeds.ac.uk

Eye (2011) 25, 529; doi:10.1038/eye.2010.212; published online 14 January 2011

Sir,

\section{Response to Khan et al}

We thank Khan et al ${ }^{1}$ for their insightful comments on our recent paper. ${ }^{2}$ Their suggestion of including FOXC2 in the screening set of genes is very interesting. It opens a possibly new aspect of an interesting extension to the associated phenotype in the reported Chinese family. We have already collected 18 genomic DNA samples from three generations of this family. Linkage to FBN1 locus cannot be ruled out by microsatellite markers. A novel missense mutation was identified in FBN1 gene, which co-segregated with the ocular phenotype (data not published). Association of single-nucleotide polymorphisms in TGF $\beta R 2$ gene was not confirmed. Obviously, this is different from the features associated to disposition to aortic dilatation and dissection of a UK family reported by Law et al. ${ }^{3} F O X C 2^{4,5}$ or other genes may be the possible genetic factors as Khan et al pointed out. Whole-genome scanning using single-nucleotide polymorphism chips is our future strategy, which we hope can answer the question shortly.

\section{Conflict of interest}

The authors declare no conflict of interest.

\section{References}

1 Khan K, Ali M, Inglehearn C. A possible genetic answer to a recently reported novel phenotype. Eye 2011; 25: 529.

2 Shen $\mathrm{W}, \mathrm{Fu} \mathrm{Q}$, Sui $\mathrm{R}, \mathrm{Wu}$ J, Liu L. Unique phenotype in a Chinese family pedigree: ectopia lentis with varicose great saphenous vein. Eye 2010; 24(10): 1614-1617.

3 Law C, Bunyan D, Castle B, Day L, Simpson I, Westwood G et al. Clinical features in a family with an $\mathrm{R} 460 \mathrm{H}$ mutation in transforming growth factor $\mathrm{b}$ receptor2 gene. J Med Gent 2006; 43: 908-916. 
4 Mellor RH, Brice G, Stanton AW, French J, Smith A, Jeffery S et al. Mutations in FOXC2 are strongly associated with primary valve failure in veins of the lower limb. Circulation 2007; 115(14): 1912-1920.

5 Smith RS, Zabaleta A, Kume T, Savinova OV, Kidson SH, Martin JE et al. Haploinsufficiency of the transcription factors FOXC1 and FOXC2 results in aberrant ocular development. Hum Mol Genet 2000; 9(7): 1021-1032.

W Shen ${ }^{1,3}, \mathrm{Q} \mathrm{Fu}{ }^{1,3}, \mathrm{FX} \mathrm{X}^{2}, \mathrm{~L} \mathrm{Liu}{ }^{1}$ and $\mathrm{R} \mathrm{Sui}{ }^{2}$

${ }^{1}$ Department of Ophthalmology, First Affiliated Hospital of Second Military Medical University, Shanghai, PR China

${ }^{2}$ Department of Ophthalmology, Peking Union

Medical College Hospital, Beijing, PR China

${ }^{3}$ These authors contributed equally to this work.

E-mail: hrfsui@yahoo.com

Eye (2011) 25, 529-530; doi:10.1038/eye.2010.214; published online 14 January 2011

Sir,

Acute endophthalmitis after cataract surgery at a referral centre in Northern Taiwan: review of the causative organisms, antibiotic susceptibility, and clinical features

We read with interest the study by $\mathrm{J}-\mathrm{H}$ Cheng et $a l^{1}$ describing the bacterial isolates and treatment outcomes of endophthalmitis after cataract surgery at a referral centre in Northern Taiwan. However, there are a few issues that we would like to discuss, especially regarding the information on presenting and final visual acuity (VA) specified to the causative organisms, and the choice of the intravitreal antibiotics.

As the authors state, the poorer visual outcome in their study (only 7 (11.9\%) of the 59 patients had a final VA of $>20 / 40$ ) may indeed be partly explained by the high percentage of more virulent organisms. Unfortunately, detailed information on both the presenting VA and the final VA for all types of bacterial cultures is not provided, except for the information that $1(7.7 \%)$ out of the 13 patients with a bacterial culture of Pseudomonas aeruginosa achieved a final VA better than 5/200.

The presenting VA and final VA for the 8 patients with a culture of Staphylococcus aureus and the 25 patients with a negative bacterial culture would be of special interest, as the quantities of these groups make them major determinants in the overall final VA. In literature, the percentage of patients achieving a final VA $>20 / 40$ range from 20.0 to $45.0 \%$ for $S$. aureus and from 55.3 to $58.3 \%$ for a negative bacterial culture..$^{2-4}$ As known from previous studies, presenting VA is a major determinant in final treatment outcome., ${ }^{2,5}$ Details on presenting VA and final VA, especially for $S$. aureus cultures and negative bacterial cultures, may therefore provide essential information on the poor overall outcome in their study and would improve the ability to compare their data with previous studies.

Regarding optimal antibiotic treatment, the authors correctly emphasize the importance of geographical variations as well as the need for periodic susceptibility testing to anticipate (changes in) the microbiological spectrum and antibiotic sensitivities. Surprisingly however, they state that the use of vancomycin and amikacin still provides good coverage for pathogens after cataract surgery in their region, despite the fact that their own data do not support this statement. Their reported susceptibility to amikacin was $89.5 \%$ for Gram-negative isolates and $90.9 \%$ for Gram-positive isolates, compared with 94.7 and $100 \%$ susceptibility to ceftazidime. Using ceftazidime instead of amikacin may positively influence the future treatment outcome in acute postoperative bacterial endophthalmitis after cataract surgery for the population in Northern Taiwan.

\section{Conflict of interest}

The authors declare no conflict of interest.

\section{References}

1 Cheng J-H, Chang Y-H, Chen C-L, Chen Y-H, Lu D-W, Chen J-T. Acute endophthalmitis after cataract surgery at a referral centre in Northern Taiwan: review of the causative organisms, antibiotic susceptibility, and clinical features. Eye 2010; 24: 1359-1365.

2 Pijl BJ, Theelen T, Tilanus MA, Rentenaar R, Crama N. Acute endophthalmitis after cataract surgery: 250 consecutive cases treated at a tertiary referral center in the Netherlands. Am J Ophthalmol 2010; 149: 482-487.

3 Endophthalmitis Vitrectomy Study Group. Microbiologic factors and visual outcome in the endophthalmitis vitrectomy study. Am J Ophthalmol 1996; 122: 830-846.

4 Lalwani GA, Flynn Jr HW, Scott IU, Quinn CM, Berrocal AM, Davis JL et al. Acute-onset endophthalmitis after clear corneal cataract surgery (1996-2005). Clinical features, causative organisms, and visual acuity outcomes. Ophthalmology 2008; 115: $473-476$

5 Endophthalmitis Vitrectomy Study Group. Results of the Endophthalmitis Vitrectomy Study: a randomized trial of immediate vitrectomy and of intravenous antibiotics for the treatment of postoperative bacterial endophthalmitis. Arch Ophthalmol 1995; 113: 1479-1496.

\section{BJ Pijl and N Crama}

Department of Ophthalmology, Radboud University Nijmegen Medical Centre, Nijmegen, The Netherlands

E-mail: n.crama@ohk.umcn.nl

Eye (2011) 25, 530; doi:10.1038/eye.2010.213; published online 21 January 2011

Sir,

\section{Response to Pijl and Crama}

We thank Drs Benjamin Pijl and Niels Crama ${ }^{1}$ for their instructive comments regarding our article. ${ }^{2}$ Benjamin Pijl and Niels Crama highlighted the following introductory statement: 'The information of presenting and final visual acuity (VA) specified to the causative organisms and the choice of the intravitreal antibiotics.'

The aim of our paper was to show the spectrum of bacterial isolates that caused endophthalmitis after 